\title{
Answer to the Letter to the Editor of Shen YW, et al. concerning "Complications of cervical total disc replacement and their associations with heterotopic ossification: a systematic review and meta-analysis" by N. Hui, et al. [Eur Spine J; 2020; 29(11):2688-2700]
}

\author{
Ralph J. Mobbs ${ }^{1}$
}

Received: 16 March 2021 / Accepted: 17 March 2021 / Published online: 7 April 2021

(c) The Author(s), under exclusive licence to Springer-Verlag GmbH Germany, part of Springer Nature 2021

We would like to thank the authors of the Letter to the Editor for their interest in our recent publication and comments on it. The authors raised two important issues that are worthy of discussion.

First, our results suggested that dysphagia was inversely associated with heterotopic ossification (HO) after adjustment for age and length of follow-up [1]. We agree with your assessment that HO shares many risk factors with postoperative dysphagia such as smoking, long operation time, inadequate hemostasis and retraction. As the authors of this letter pointed out, our theory that intact and undamaged peripheral nerve containing progenitor cells in the endoneurium may play a role in $\mathrm{HO}$ formation should be interpreted with caution. Such theory has not been proven, to our best knowledge, in any in vivo or in vitro studies.

Second, we have performed correlation analyses on the association between high-grade HO (McAfee or Mehren grade III and IV) and adjacent segment degeneration (ASDegeneration). In midterm follow-up ( $\geq 2$ and $<5$ years), high-grade $\mathrm{HO}$ was not associated with ASDegeneration $\left(n=6, p=0.52, R^{2}=0 \%\right)$. The insignificant result in midterm follow-up can be explained by the fact that four out of six studies reported zero rate of high-grade HO [2-5]. By contrast, high-grade $\mathrm{HO}$ was positively associated with ASDegeneration $\left(n=8, p=0.0052, R^{2}=58.9 \%\right)$, in studies with $\geq 5$-year follow-up. As discussed in our original study, the positive association between $\mathrm{HO}$ and ASDegeneration could be due to altered biomechanics by $\mathrm{HO}$ formation or a natural degenerative process.

Ralph J. Mobbs

ralphmobbs@hotmail.com

1 NeuroSpineClinic, Prince of Wales Private Hospital, Suite 7, Level 7, Randwick, New South Wales 2031, Australia
We would like to thank the authors of this letter again for their comments and suggestions and hope the above response could clarify their concerns.

\section{References}

1. Hui N, Phan K, Cheng HM, Lin YH, Mobbs RJ (2020) Complications of cervical total disc replacement and their associations with heterotopic ossification: a systematic review and meta-analysis. Eur Spine J 29:2688-2700

2. Li J, Liang L, Ye XF, Qi M, Chen HJ, Yuan W (2013) Cervical arthroplasty with discover prosthesis: clinical outcomes and analysis of factors that may influence postoperative range of motion. Eur Spine J 22:2303-2309

3. Wang Q, Cheng H, Mao Z, Qi X, Zhang M, Chen Y (2011) Clinical and radiographic results after treatment of cervical degenerative disc disease with the Bryan disc prosthesis: a prospective study with 2-year follow-up. Acta Orthop Belg 77:809-815

4. Sun Q, Sun L, Li P, Zhao H, Hu H, Chen J, Li J (2016) A comparison of zero-profile devices and artificial cervical disks in patients with 2 noncontiguous levels of cervical spondylosis. Clin Spine Surg 29:E61-E66

5. Liu S, Song Y, Liu L, Wang L, Zhou Z, Zhou C, Yang X (2016) Clinical and radiologic comparison of dynamic cervical implant arthroplasty and cervical total disc replacement for single-level cervical degenerative disc disease. J Clin Neurosci 27:102-109

Publisher's Note Springer Nature remains neutral with regard to jurisdictional claims in published maps and institutional affiliations. 